\title{
Do different educational pairings lead to different fertility outcomes? A cohort perspective for the Greek case
}

\author{
Christos Bagavos*
}

\begin{abstract}
The paper investigates fertility differentials by educational pairing in a cohort perspective. Based on Greek census data, the analysis generates empirical results in demographic areas that have yet to be fully explored, such as the quantum of completed cohort fertility by the partners' educational levels (particularly among homogamous, hypergamous, and hypogamous couples), permanent childlessness among highly educated couples and the completed fertility patterns by birth order across different educational pairings. The findings confirm the shift from the traditional pattern of educational hypergamy (women marrying up) to hypogamy (the woman is more educated than the man) and to medium and high educational homogamy. They also document that the differentials in fertility patterns by couples' levels of education appear to be related more to the tempo than the quantum of fertility, with the notable exception of the less educated homogamous couples; the completed fertility levels are significantly higher among this particular educational pairing than among the other educational pairings. The study suggests that educational pairing is likely to be an important topic in the investigation of human reproduction, particularly given that the increase in female educational levels and the shifts in traditional gender roles are leading to changes in fertility decisionmaking processes.
\end{abstract}

* Christos Bagavos, Department of Social Policy, Panteion University of Social and Political Sciences, Athens

Email: christosbagavos@gmail.com 


\section{Introduction}

Education has long been seen as playing a significant role in shaping fertility outcomes, and has been characterised as a main determinant of economic wellbeing later in life (Thomson et al. 2013). In both the micro-economic model introduced by Becker's New Home Economics (Becker 1960) and the cultural approaches to fertility that focused on the role of education in the diffusion of new values and ideas (Lesthaeghe 1995), it was argued that the educational gradient is closely associated with fertility tempo and quantum, and especially with persistent differentials in fertility outcomes (Sobotka et al. 2015; Wood et al. 2014). Scholars have also asserted that education is linked to fertility through mechanisms related to field-specific socialisation and self-selection (Hoem et al. 2006; Van Bavel 2010). Indeed, educational orientation has been shown to affect the type and the sector of employment individuals choose, and is thus linked to differences in the earning potential and reproductive behaviour of individuals.

In the existing literature, the dimensions of the association between education and fertility mentioned above have mainly been investigated among women, and especially among highly educated women. By contrast, there is relatively little demographic research on this relationship among men. The limited empirical findings on this issue suggest that the negative association between education and fertility does not vary by gender (Zhang 2011), but that men and women with similar educational levels have different fertility rates (Nisén et al. 2014) and different patterns of childlessness (Kravdal and Rindfuss 2008). It has also been shown that the association between the long-term changes in the TFR and the trends in education-specific fertility levels differ between men and women (Tragaki and Bagavos 2014).

In addition, even though it is widely accepted that interactive processes among partners are significant determinants of fertility behaviour, only a few empirical studies have looked at the question of how partners' educational levels interact with their fertility outcomes. Most of these studies examined fertility differentials between educationally homogamous and heterogamous couples, based on the theoretical assumption - and, to a lesser extent, empirical evidence - that the former tend to have more children than the latter (Corijn et al. 1996; Huber and Fieder 2011; Mascie-Taylor 1986; Testa et al. 2014; Thomson 1997). The relatively recent reversal of the gender gap in education, or the increase in the number of highly educated women resulting from the growth in female participation in higher education (Grow and Van Bavel 2015; Van Bavel 2012; Esteve et al. 2012), has led scholars to develop a renewed interest in investigating the question of how the educational attainment of couples shapes their fertility behaviour (Nitsche et al. 2015). It is important to note that this reversal has been accompanied by significant shifts in patterns of assortative mating, whereby women are increasingly likely to be in either a hypogamous relationship in which the woman is more educated than her partner, or in a homogamous relationship in which both partners are highly educated. It follows that the transition from the traditional pattern of women 
'marrying up' (i.e., forming a hypergamous relationship in which the male partner is more educated than the female partner) to the more recent pattern of women 'marrying down' (i.e., forming a hypogamous relationship) affects the bargaining power and the decision-making processes of the partners regarding employment, financial resources, and the division of family work by gender. These shifts may in turn be expected to influence fertility.

We have two main motivations for conducting our study. First, given that in Greece men and women with similar educational levels have different fertility rates (Bagavos and Tragaki 2014), it is likely that education is related not only to varying patterns of union formation, but to varying patterns of fertility behaviour among couples. Second, the increase in women's educational levels over the last 30 years has modified family formation patterns in Greece. This trend is likely to affect fertility in two main ways. First, it could have a 'compositional' effect on overall fertility levels, as the relative shares of homogamous and heterogamous couples change. Second, it implies a shift away from hypergamous relationships (in which the man is more educated) and towards hypogamous relationships (in which the woman is more educated), and an increase in the educational levels of homogamous couples. If these developments lead to an increase in women's bargaining power, they could affect decisions made at the couple level regarding labour market participation and the timing and quantum of fertility, and the differences in the fertility levels of various educational pairings. Thus, in this paper we seek to analyse the differences in the fertility levels of homogamous and heterogamous (hypergamous/hypogamous) couples, as well as fertility differentials among educationally homogamous couples. Investigating these questions can help us gain a better understanding of the relationship between education and fertility in Greece. Our study thus extends existing analyses of the association between various educational pairings and fertility outcomes by educational level (Rendall et al. 2010), educational field (Bagavos 2010), and male educational attainment (Tragaki and Bagavos 2014).

In our study, we use data on cohorts born between 1945 and 1969 to analyse various aspects of couples' fertility patterns from a cohort perspective. In particular, we examine the timing of entry into parenthood; the probability of having a first, a second, and a third birth; the level of completed fertility; and the effective reproductive lifetime, or the difference between the mean ages at the last and the first birth. While this is largely an explorative and descriptive exercise, it provides new insights into how couples' educational levels interact with fertility tempo and quantum. Thus, our analysis generates empirical results in demographic areas that have yet to be fully explored, such as the quantum of completed cohort fertility by the partners' educational levels (particularly among homogamous, hypergamous, and hypogamous couples), permanent childlessness among highly educated couples (and not just among highly educated women), and the completed fertility patterns by birth order across different educational pairings. 


\section{Theoretical considerations, empirical findings, and the Greek context}

Educational homogamy is expected to result in higher fertility than educational heterogamy. It is generally assumed that the partners in an educationally homogamous relationship are likely to have similar values (Corijn et al. 1996). In addition, as educational homogamy appears to facilitate agreement and understanding between the partners, these couples are likely to have shared goals (Thomson 1990) and similar lifestyles (Kalmijn 1991). If these arguments are correct, we can expect to find that fertility levels differ not just between homogamous and heterogamous couples, but across homogamous couples (Corijn et al. 1996). Whether the partners in a couple have common values might affect their fertility, but educationally homogamous couples do not necessarily have higher fertility levels than heterogamous couples. For example, if less educated homogenous couples share an orientation towards traditional values whereas highly educated homogenous couples embrace modern, individualistic values; then the former group of couples may be expected to have higher fertility than the latter group of couples.

Highly educated homogamous couples are also predicted to have low fertility levels by micro-economic models of fertility (Becker 1993). If the partners in a couple try cope with the problem of forgone earnings related to the decision to have a (or an additional) child by choosing to specialise in paid work or childrearing tasks, then an increase in the woman's educational gradient, and thus in her earning potential, leads to lower specialisation gains associated with marriage, and to lower fertility. This is particularly likely to be the case if the partners are both highly educated. By contrast, models that focus on the advantages of pooling resources (Oppenheimer 1997) have questioned the specialisation model, and have emphasised the increasing importance of dual-earner couples. These approaches have suggested that, compared to male-breadwinner couples, dual-earner couples are more flexible and are better able to adapt to labour market challenges; thus, among these couples the returns to marriage do not necessarily decline as the partners become more similar in their earning potential. This theory predicts that, compared to their less educated counterparts, couples in which both partners are highly educated may be expected place a similarly high value on gender equality, and to have more stable employment situations that help them cover the costs of childrearing. Thus, highly educated couples would be expected to have higher fertility than less educated couples (Nitsche et al. 2015; Dribe and Stanfors 2010).

The argument that educationally homogamous couples have higher fertility than educationally heterogamous couples has, however, been challenged by microeconomic and bargaining models of fertility. According to one micro-economic perspective, hypergamous couples are expected to have higher fertility than other couples because the man is likely to specialise in paid work while the woman is likely to specialise in childrearing tasks. However, bargaining approaches have posited that educationally homogamous and heterogamous couples will differ in 
their fertility levels because they differ in their fertility decision-making processes (Nitsche et al. 2015; Neyer et al. 2013; Hener 2010). For example, Thomson has argued that there is a 'power rule' in fertility decision-making (Thomson 1990), whereby a woman who has an equal or a larger share of the resources in her partnership is better able to cope with the conventional gender division of domestic work by bargaining for either more help with these tasks from her (male) partner, or for purchasing support from the market. Thus, this woman may be expected to have higher fertility than a woman whose partner has more resources than she does (Nitsche et al. 2015). Accordingly, as the female partner's bargaining power is highest among hypogamous couples (Klesment and Van Bavel 2015), these couples are expected to have higher fertility than other educational pairings.

The association between couples' educational levels and fertility outcomes can also be investigated with respect to changes in gender roles. Indeed, a number of scholars have argued that gender egalitarianism is particularly relevant for high fertility (Esping-Andersen and Billari 2015; Neyer et al. 2013; McDonald 2000a). If both of the partners in a couple are highly educated, they are likely to have similar views on gender equality and to place a high value on equal gender roles - and are thus expected to have higher fertility than other couples (Nitsche et al. 2015). However, gender equality is a complex and multi-dimensional issue. Fraser (1994), McDonald (2000a, 2000b), and, more recently, Neyer et al. (2013) pointed out that there is a distinction between gender equality and gender equity: the former refers to gender differences in domains like work, education, family, and childrearing tasks; while the latter refers to perceptions of fairness and opportunities (Esping-Andersen and Billari 2015). Although gender equity is considered to be more relevant for fertility than gender equality, gender equity can be difficult to measure. Thus, gender equality is often used as a surrogate predictor for fertility levels. However, the decision to use indicators of gender equality to measure how gender equity shapes fertility outcomes has resulted in inconclusive findings. This is primarily because most analyses do not consider all three dimensions of gender equality - namely, employment, financial resources, and family work - that contribute to the ability to maintain a household, the degree of agency, the capacity to choose, and the degree of gender equity in household and care work (Neyer et al. 2013). It follows that although the increase in the proportion of women who are highly educated could be seen as a driving force in the trend towards more equal gender roles, it does not necessarily lead to higher fertility. In fact, adopting gender-egalitarian practices seems to be a necessary precondition for reaching an adequate degree of gender equity, and therefore for achieving relatively high fertility levels. In other words, although highly educated homogamous couples are more likely than other educational pairings to place a high value on equal gender roles, highly educated partners might still have relatively low fertility until 'gender egalitarianism has achieved dominant normative status' (Esping-Andersen and Billari 2015) among these couples. This dominant normative status with respect to gender egalitarianism probably applies to the dual-career or 'power' couples (Dribe and Stanfors 2010) who have been shown to be more 
likely to continue having children and to be less likely to separate than simple dual-earner highly educated couples or other educational pairings. In addition, even if educationally homogamous couples have convergent marketable skills-which, according to Becker $(1960,1993)$, implies lower returns to marriage-differences in fertility may persist among these couples. In particular, differences in the fertility levels of highly and less educated homogamous couples are less likely to be attributable to differences in rational choices than to differences in perceptions of gender inequality; i.e., unequal gender roles may be seen as fair and just by less educated couples, but as unfair and unjust by highly educated couples.

Empirical studies on the interactions between couples' educational levels and fertility outcomes have generated mixed results, which suggests that these interactions are subject to specific dimensions related to parity, birth cohort, the social context in which childbearing occurs, and the definitions of educational groups. In particular, it has been found that the female partner's educational attainment is more relevant than that of her male partner for parenthood in Germany (Bauer and Jacob 2009) and for completed fertility in the USA (Sorenson 1989). In addition, Mascie-Taylor (1986), using British data, found that educationally homogamous couples have a higher rate of completed fertility than educationally heterogamous couples. By contrast, it has been shown that highly educated homogamous couples have a lower probability of parenthood (Bauer and Jacob 2009) and a greater tendency to delay their first birth (Corijn et al. 1996) than less educated homogamous couples in Germany and in the Netherlands and Flanders, respectively. It has further been shown that highly educated homogamous couples are less likely than hypogamous couples to remain childless, but that they are less likely to become parents than hypergamous couples in Germany (Wirth 2007, cited by Nitsche et al. 2015). For Sweden, Dribe and Stanfors (2010) found that 'power couples' - or couples in which both partners are highly educated and have high-powered careers - are considerably more likely than other educational pairings to continue having children after they have had a first child. In a recent crosscountry study, Nitsche et al. (2015) found that in many countries, highly educated homogamous couples are more likely to delay the transition to parenthood and to have a second or a third child than either hypogamous couples (in which the female partner is more educated) or hypergamous couples (in which the male partner is more educated). In short, even if the distinction between the timing- and the quantum-related effects on fertility of couples' educational levels are not always obvious, there is clear empirical evidence that different educational pairings are associated with different fertility outcomes.

The existing empirical findings also suggest that whether the male or the female partner's educational level has a greater impact on fertility decision-making and fertility outcomes strongly depends on country-specific social and institutional factors. Among the birth cohorts in Greece who are the focus of our study, the trends towards rising female educational levels and the reversal of gender inequality in education have not necessarily translated into gender balance in labour market participation or in the division of family and household tasks. Over the past 20 years, 
the employment rates of highly educated Greek women have remained lower than those of highly educated Greek men, and have not differed significantly from those of men with low or medium levels of education (Bagavos and Tragaki, 2014). In addition, employment rates and educational levels in Greece have different associations with period fertility depending on gender. While employment seems to be a precondition for fatherhood regardless of the man's educational level, nonemployment is linked with higher fertility among women, and particularly among women with low or (to a lesser extent) medium levels of education (Bagavos and Tragaki 2014). The amount of time individuals spend on household tasks also varies considerably by gender. In their study of Labour Force Survey (LFS) data on the reasons for inactivity by age and sex in Greece, Lagoudakou and Bagavos (2016) found that a girl who is currently age 15 is expected to spend 10 years of her total life expectancy performing household and family tasks, whereas the corresponding figure for a boy of the same age is only one year. Differences in institutional contexts are also linked to differences in fertility levels. Rendall et al. (2010) noted that in Greece, the timing and the quantum of first childbearing differs markedly by female educational level, with the gap being especially large between women with high and low levels of education. They attributed these patterns to the family policy regime in Greece, which makes it difficult for women to combine employment and motherhood.

We refer to these contextual factors in formulating hypotheses regarding couples' expected fertility outcomes depending on the partners' educational levels in Greece. In line with several previous studies, we might expect to find that educationally homogamous couples tend to have more children than educationally heterogamous couples. However, the social and institutional contexts in Greece could imply that there are pronounced fertility differentials across homogamous couples, and especially between those with low and high educational levels. In Greece, being in employment is more likely to be a precondition for male than for female fertility; labour market participation rates differ by gender; and female employment is negatively associated with fertility, largely because of the lack of child care. Given these conditions, less educated couples may be expected to have higher fertility than highly educated homogamous couples. Thus, among the cohorts under study, the shared goals of less educated homogamous couples might include having a relatively large number of children in a male-breadwinner family, whereas the shared goals of highly educated homogamous couples might include prioritising the labour market participation of both partners over having children. These differences in goals might also prove relevant when we compare the fertility of less educated homogamous couples with the fertility of various types of heterogamous couples, either because the partners in hypergamous couples do not have the same fertility expectations, or because even in a hypogamous couple, the woman's bargaining power remains limited given the social and institutional conditions. 


\section{Data and methods}

In this paper, we analyse fertility outcomes by couples' educational levels for fiveyear cohorts who were born in Greece between 1945 and 1969. The data on both partners' educational levels, and on each female partner's number of children ever born and ages at the birth of her first and last child, are drawn from the three most recent censuses. The census data for 1991 and 2001 were provided by Integrated Public Use Microdata Series, International (IPUMS 2015), a project dedicated to collecting and distributing census data from around the world; and the census data for 2011 came from the Hellenic Statistical Authority (EL.STAT. 2015). To avoid inconsistencies in the censoring of fertility histories, we investigated the fertility patterns of women using 1991 census data for the cohorts born between 1945 and 1949, 2001 census data for the cohorts born in the 1950s, and 2011 census data for the cohorts born in the 1960s. Thus, for all of the cohorts studied, the end of the reproductive period is set at a minimum age of 42 . However, since information on the years of the first and the last birth was not available in the 1991 census, 2001 census data were used to investigate the timing of the first and the last birth for the cohorts born in 1945-49. Full population data were used for the cohorts born in the 1960s (EL.STAT. 2015: 2011 census), and census micro-data were used for the cohorts born between 1945 and 1959 (IPUMS 2015: 1991 and 2001 censuses).

We restricted our analyses to native-born women and men; i.e., to native-born couples. We imposed this restriction because we were interested in examining the association between educational attainment and fertility among couples who had attended Greek educational institutions, and who were exposed to the same country-specific contextual factors that might have shaped their fertility outcomes. In addition, using cohort data from censuses carried out in different years implicitly assumes that the population is closed during the reproductive years; an assumption that can reasonably be made for the native-born population only (Rendall et al. 2010). Finally, including only native-born couples in our study sample allows us to avoid the problem of inconsistencies in the educational levels of natives and migrants; an issue that is of particular importance in the census data (Tsimbos 2006).

Information on the educational gradient of couples was gathered from the data on the educational levels of men and women who were living as a couple at the time of the census. The term 'couples' refers to married couples (in which both partners were alive at the time of the census) and to unmarried couples who were living together at the time of the census (or 'in a consensual union' in the 2011 census). For the 2011 census, this information was provided by EL.STAT. (2015). For the 1991 and 2001 censuses, this information was accessed using the 'Attach Characteristics' option of the IPUMS (2015) data, which allowed us to attach information on the spouse to a respondent's observation ${ }^{1}$.

1 We thank Tim Moreland from the IPUMS Team, who has directed our attention to this option. 
A three-category educational attainment classification (low, medium, and high) based on the International Standard Classification of Education (ISCED) was applied to the male and female partners in each couple. Individuals with no education, primary education, or lower secondary education (three years after the completion of six years of primary education) were assigned to the category 'low education' (ISCED 1 or 2). Individuals with completed upper secondary or postsecondary non-tertiary education were assigned to the category 'medium education' (ISCED 3 or 4). Finally, individuals with low or high levels of tertiary education were assigned to the category 'high education' (ISCED 5 or 6).

The mean numbers of children per woman by the couples' educational levels and the female birth cohort were computed based on the reported number of children ever born alive'. Since this information makes it possible to discern the number of women with at least one, two, or three children, we were able to estimate first-, second- and third-birth (cumulative) probabilities for the various educational pairings and birth cohorts. For first births, we analysed the timing and quantum of entry into motherhood based on women's responses to the question on the 'year of birth of the first child'. Based on this information, we computed the first-birth probabilities by the female cohort, by age, and by the couples' educational levels. Then, using a first birth life table (Rendall et al. 2010; Chen and Morgan 1991), we converted these probabilities (hazards) into cumulative proportions of women in the female cohort and couples' educational clusters for having a first birth by given ages (cumulative first birth probabilities). The 'year of birth of the last child' was also used to compute the effective reproductive lifetime-estimated by the difference between the mean ages at the last and the first birth-by birth cohorts and educational pairings.

In our paper we opted to use a cohort approach that allowed us to estimate the real completed fertility of several birth cohorts. But because the respondents were asked retrospectively about their number of children ever born the main implication of this choice is that it was not easy to link socio-economic factors with fertility behaviour at the time when it actually occurred. While this shortcoming might be considered of limited importance when examining the impact of a long-standing individual characteristic like educational level, it is likely to be more relevant when studying the effects of other characteristics such as the timing and duration of participation in the labour market. Our choice of methodological approach has to be seen in relation to the census data used in our analysis. Incomplete counts and misstatements in reconstructing individual (in our case cohort) histories are the most common problems that can arise when using census data to study fertility outcomes. Incomplete counts are related to errors of omission (children who died or left home, children born of a husband other than the current husband, and children given away for adoption) and to errors of inclusion (foetal deaths reported as children who died in infancy, children born to another wife of the current husband, and adopted children). Misstatements in reconstructing birth cohort histories may also be related to mortality and to international migration. Nevertheless, our use of data derived 
from successive censuses greatly mitigates these potential drawbacks and allows us to assume that our descriptive analysis is based on reasonably sound data. ${ }^{2}$

Another important issue that arises when using census data to study fertility outcomes is how to deal with factors such as remarriage, cohabitation, divorce, stepparenting and adoption. Indeed, the potentially distorting effects of these factors raise the question of whether census data are appropriate for examining couples' fertility outcomes. We argue that these factors do not affect the accuracy of our data since they are of limited importance during the period of study; thus, we assume that our data largely reflect first partnerships. It should be noted that in Greece, cohabitation status has only very recently been recognised by law (2009). While this status was taken into account in the 2011 census data, cohabitation remains rare in Greece. Similarly, rates of divorce and remarriage - and thus of step-parentinghave been very low in Greece. According to census data the proportion of Greek women aged 30-49 who are divorced remains small, having increased from $2 \%$ in 1991 to just $6 \%$ in 2011. Moreover, rates of adoption are low in Greece, as the process of adoption is governed by court orders that require prospective parents to meet a number of financial and socio-economic criteria.

\section{Results}

In the following, we present our results on fertility levels and trends by couples' educational levels for five-year age groups of the 1945-69 birth cohorts. The educational pairings of homogamous couples are presented for couples with low, medium, and high levels of education. The remaining six categories of educationally heterogamous couples are classified according to whether they are hypergamous (the man is more educated) or hypogamous (the woman is more educated). In addition, we provide more detailed results by single cohort and for each of the nine educational pairings in Appendix A.1.

Before presenting our descriptive results, we should point out that they might be subject to certain selection biases: i.e., individuals are selected into entering a partnership and parenthood, and are also selected as they choose to stay in a partnership. The results presented below should therefore be interpreted with these potential biases in mind. We first compare changes in couples' distributions by the partners' educational levels across cohorts (Table 1). It is clear that these developments are heavily influenced by the increasing female education gradient, which implies that the proportions of women with low levels of education were decreasing, while the proportions of women with medium and high levels of

2 In order to estimate how these drawbacks can affect our results we also estimated fertility outcomes by the partners' educational levels for the birth cohorts 1945-49 and 1950-59 using data from the 2001 and 2011 censuses and from the 1991 and 2001 censuses, respectively. Based on this analysis, we concluded that the differences were of extremely limited importance. 
Table 1:

Per cent distribution of partners' educational levels (five-year groups of the 1945-74 birth cohorts)

\begin{tabular}{|c|c|c|c|c|c|c|}
\hline \multirow{2}{*}{$\begin{array}{l}\text { Partners' } \\
\text { educational levels* }\end{array}$} & \multicolumn{6}{|c|}{ Cohort groups } \\
\hline & 1945-49 & $1950-54$ & 1955-59 & 1960-64 & 1965-69 & 1970-74 \\
\hline Homogamy & 77 & 70 & 66 & 63 & 60 & 59 \\
\hline Low & 60 & 47 & 38 & 33 & 23 & 16 \\
\hline Medium & 10 & 13 & 17 & 17 & 20 & 26 \\
\hline High & 6 & 9 & 10 & 13 & 17 & 17 \\
\hline Heterogamy & 23 & 30 & 34 & 37 & 40 & 41 \\
\hline $\begin{array}{l}\text { Hypergamy (man } \\
\text { more educated) }\end{array}$ & 17 & 19 & 21 & 18 & 17 & 16 \\
\hline Low_High & 2 & 2 & 2 & 2 & 1 & 1 \\
\hline Low_Medium & 9 & 9 & 10 & 8 & 7 & 6 \\
\hline Medium_High & 6 & 8 & 9 & 8 & 8 & 9 \\
\hline $\begin{array}{l}\text { Hypogamy (woman } \\
\text { more educated) }\end{array}$ & 6 & 11 & 14 & 19 & 24 & 25 \\
\hline Low_High & 0 & 1 & 1 & 2 & 3 & 2 \\
\hline Low_Medium & 4 & 7 & 9 & 12 & 13 & 14 \\
\hline Medium_High & 2 & 3 & 4 & 5 & 8 & 9 \\
\hline
\end{tabular}

Source: Author's own estimations based on IPUMS data for the 1991 and 2001 censuses and on EL.STAT. data for the 2011 census.

${ }^{*}$ We thank one of the reviewers who advised us to use the above-mentioned category coding and labels.

education were increasing. Homogamous couples became less common, declining from 77 per cent among the oldest couples (in which the female partner was born between 1945 and 1949) to 59 per cent among the youngest couples (in which the female partner was born between 1970 and 1974). Conversely, heterogamous couples became more common, increasing from 23 per cent among the oldest couples to 41 per cent among the youngest couples. There were also pronounced changes in the per cent distributions across homogamous couples: 60 per cent of the oldest couples, but just 16 per cent of the youngest couples, had low levels of education. By contrast, the shares of homogamous couples with medium or high levels of education grew across these cohorts, from 10 to 26 per cent and from six to 17 per cent, respectively. Hypogamous couples also became increasingly common: from the oldest to the youngest cohorts, there was an increase in the share of couples in which the woman had a high level of education and the man had medium level of education (from two to nine per cent), and in which the woman had a medium level of education and the man had a low level of education (from four to 14 per cent). Meanwhile, the share of hypergamous couples in which the man had a high level of 
Table 2:

Mean number of children per women by educational pairing (five-year groups of the 1945-1969 birth cohorts)

\begin{tabular}{lccccc}
\hline \multirow{2}{*}{$\begin{array}{l}\text { Partners' } \\
\text { educational levels }\end{array}$} & \multicolumn{5}{c}{ Cohort groups } \\
\cline { 2 - 6 } & $\mathbf{1 9 4 5 - 4 9}$ & $\mathbf{1 9 5 0 - 5 4}$ & $\mathbf{1 9 5 5 - 5 9}$ & $\mathbf{1 9 6 0 - 6 4}$ & $\mathbf{1 9 6 5 - 6 9}$ \\
\hline Homogamy & 2.21 & 2.17 & 2.15 & 2.13 & 2.06 \\
Low & 2.30 & 2.30 & 2.34 & 2.33 & 2.33 \\
Medium & 1.88 & 1.89 & 1.92 & 1.93 & 1.90 \\
High & 1.86 & 1.85 & 1.83 & 1.88 & 1.88 \\
Heterogamy & 2.00 & 1.99 & 1.99 & 2.00 & 1.98 \\
Hypogamy & 1.95 & 1.95 & 1.94 & 1.99 & 1.96 \\
Hypergamy & 2.02 & 2.01 & 2.02 & 2.01 & 2.00 \\
\hline Total* & 2.16 & 2.11 & 2.09 & 2.08 & 2.03 \\
\hline
\end{tabular}

Source: Author's own estimations based on IPUMS data for the 1991 and 2001 censuses and on EL.STAT. data for the 2011 census.

*Based on women living in a couple at the time of the census.

education and the woman had a medium level of education increased slightly across these cohorts, from six to nine per cent.

Table 2 presents the levels of completed fertility by couples' educational levels across cohorts (see also Appendix A.1). The findings confirm our assumption that homogamous couples had higher completed fertility levels than heterogamous couples. However, this gap is attributable to the relatively high fertility levels (at about 2.3 children per woman) among less educated homogamous couples, since homogamous couples with medium and (in particular) high levels of education had lower fertility than any heterogamous pairing (hypergamy or hypogamy). When highly educated homogamous couples were considered as a reference category, we found that less educated homogamous couples had higher completed fertility levels (of around $24 \%$ to $28 \%$ ) than highly educated homogamous couples; the fertility levels of the remaining educational pairings were also higher (the differences in the mean number of children varied from $1 \%$ to $+10 \%$ ) than the fertility levels of the highly educated homogamous couples.

Another noteworthy finding is that the nearly stable pattern of completed fertility by educational pairing contrasts to some extent with the decreasing trend in total cohort fertility from the cohorts born in the late 1940s to the cohorts born in the late 1960s (from 2.16 to 2.03 children per woman). We suggest that this result is related to compositional rather than to behavioural factors; in a context in which the relationship between completed fertility and couples' educational levels is stable, a decline in the share of the educational pairings with the highest fertility levels-here, 
the less educated homogamous couples-leads to a decline in total cohort fertility rates.

These findings also suggest that, even though the likelihood of entry into motherhood was similar across educational pairings, the timing of the first birth varied significantly across cohorts. In Figure 1a, we can see that the cumulative first birth probability among highly educated homogamous couples was comparable to that among the other educational pairings by age 30. At that age, highly educated homogamous were substantially less likely than other educational pairings to have entered parenthood. In addition, the differences in the first birth risks of highly educated homogamous couples and of the remaining educational pairings increased sharply across cohorts; whereas the differentials in first birth intensity ranged from around one (no difference) to almost 1.4 for the oldest cohorts, the corresponding figures for the youngest cohorts born in the late 1960s varied from 1.4 to 1.8. As expected, we found that the differentials in first childbearing were more pronounced between highly educated homogamous couples and the educational pairings that had the highest levels of completed fertility; namely, the less educated homogamous couples.

Surprisingly, however, the proportions of women who had had a first birth by the end of their reproductive lifetime differed little across cohorts and by couples' educational levels (Figure 1b). In other words, women were equally likely to have become a mother regardless of their educational pairing or birth cohort. Indeed, the differentials between highly educated homogamous couples and other educational pairings in terms of entry into parenthood were related almost exclusively to the timing, not to the quantum, of first-birth risk. This finding is clearly reflected in the changes in the figures for the mean age at first childbearing (Table 3). A transition from early to late first motherhood for the cohorts born before and after 1960 was detected for all women living in a couple. The mean age at first birth was 24.7 for the 1945-49 birth cohorts, 24 for the cohorts born in the late 1950s, and 26.1 for the cohorts born in the late 1960s. This overall shift towards having the first child at older ages was evident for all educational pairings, with the notable exception of the women in a less educated homogamous couple, among whom the first birth schedule remained rather stable. In addition, large differences in the mean age at first birth can be seen across cohorts and educational pairings. When we compared other educational pairings and highly educated homogamous couples, we found that the differences in the entry into parenthood ranged from two to five years among the 1945-49 cohorts, and from 3.3 to 8.7 years among the cohorts born in the second half of the 1960s. The differentials were smallest relative to hypogamous couples, and were largest relative to less educated homogamous couples.

Table 4 shows that differences in completed fertility levels between homogamous couples with high and low levels of education are attributable to the higher probabilities among the latter than among the former group of having a second or a third child. We also note that highly educated homogamous couples clearly had lower third-birth probabilities than hypergamous and hypogamous couples; and that these differences, while small, account for the gap in completed fertility. However, 
Figure 1:

Cumulative first birth probability by ages 30 and 42 (five-year groups of the 1945-1969 birth cohorts) - (Index 1 for highly educated homogamous couples)
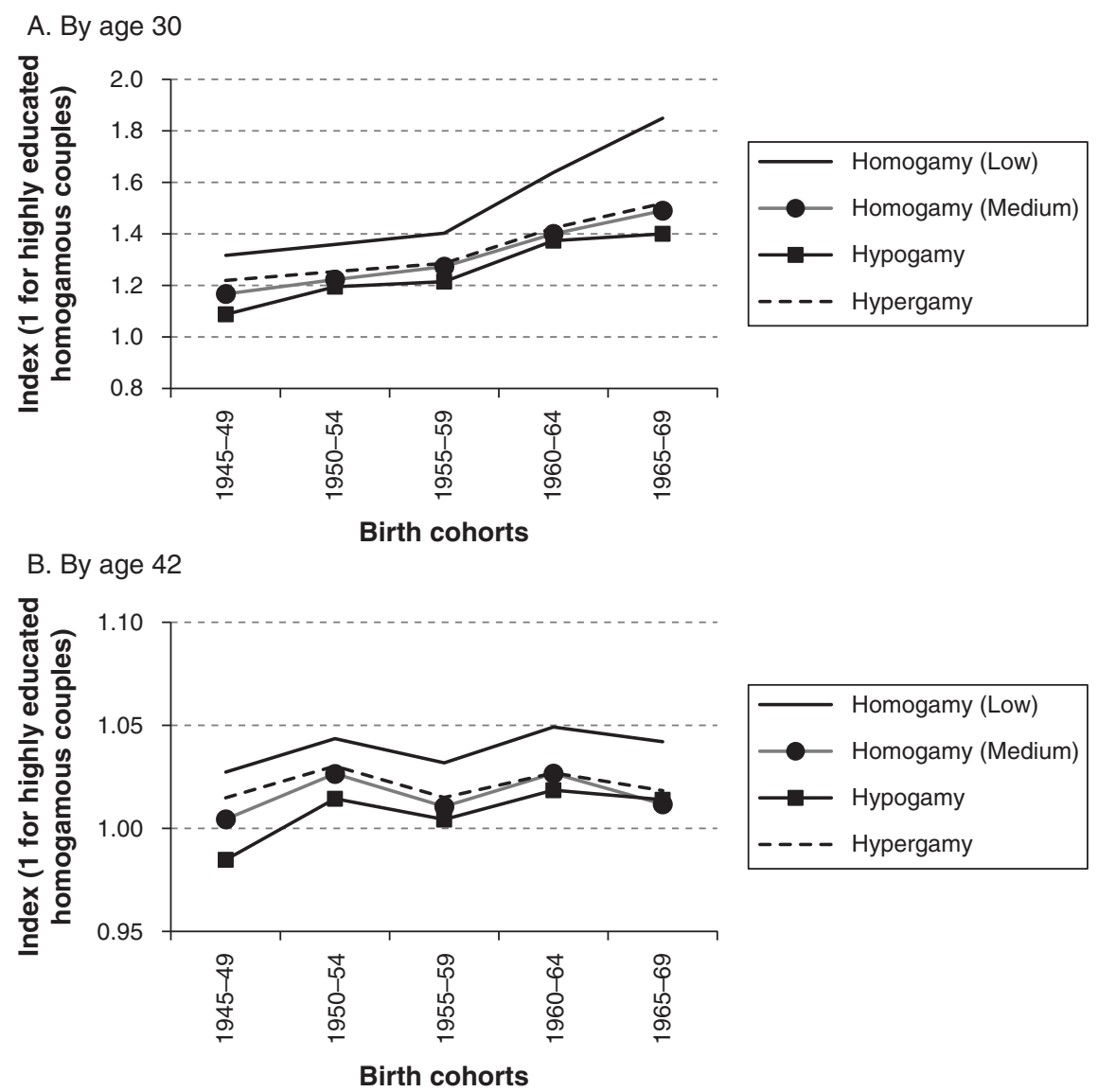

Source: Author's own estimations based on IPUMS data for the 1991 and 2001 censuses and on EL.STAT. data for the 2011 census.

we should also point out that the differences in the likelihood of having a third child between highly educated couples and the other educational pairings decreased over time and across cohorts.

Another interesting aspect of these fertility patterns is that because highly educated homogamous couples delayed their entry into parenthood, they also had a shorter effective reproductive lifetime (estimated by the difference between the mean age at the last and the first birth). Figure 2 shows that these couples had a shorter average reproductive period than all of the other couples. The differences in reproductive lifetime were most pronounced when we compared these couples with 
Table 3:

Mean age at first birth by educational pairing (five-year groups of the 1945-1969 birth cohorts)

\begin{tabular}{lccccc}
\hline Partners' & \multicolumn{5}{c}{ Cohort groups } \\
\cline { 2 - 6 } educational levels & $\mathbf{1 9 4 5 - 4 9}$ & $\mathbf{1 9 5 0 - 5 4}$ & $\mathbf{1 9 5 5 - 5 9}$ & $\mathbf{1 9 6 0 - 6 4}$ & $\mathbf{1 9 6 5 - 6 9}$ \\
\hline Homogamy (Low) & 23.6 & 22.6 & 21.7 & 21.7 & 21.8 \\
Homogamy (Medium) & 26.2 & 25.6 & 24.9 & 25.7 & 26.6 \\
Homogamy (High) & 28.7 & 28.7 & 28.5 & 29.9 & 30.5 \\
Hypogamy & 26.6 & 25.7 & 25.2 & 25.8 & 27.2 \\
Hypergamy & 25.3 & 24.9 & 24.2 & 25.0 & 25.8 \\
\hline Total & 24.7 & 24.3 & 24.0 & 24.8 & 26.1 \\
\hline
\end{tabular}

Source: Author's own estimations based on IPUMS data for the 1991 and 2001 censuses and on EL.STAT. data for the 2011 census.

Table 4:

Cumulative second and third birth probabilities by educational pairing (five-year groups of the 1945-1969 birth cohorts)

\begin{tabular}{lccccc}
\hline \multirow{2}{*}{$\begin{array}{l}\text { Partners' } \\
\text { educational levels }\end{array}$} & \multicolumn{5}{c}{ Cohort groups } \\
\cline { 2 - 6 } & $\mathbf{1 9 4 5 - 4 9}$ & $\mathbf{1 9 5 0 - 5 4}$ & $\mathbf{1 9 5 5 - 5 9}$ & $\mathbf{1 9 6 0 - 6 4}$ & $\mathbf{1 9 6 5 - 6 9}$ \\
\hline 2nd birth probability \\
Homogamy (Low) & 0.91 & 0.90 & 0.91 & 0.90 & 0.89 \\
Homogamy (Medium) & 0.82 & 0.82 & 0.82 & 0.81 & 0.79 \\
Homogamy (High) & 0.81 & 0.80 & 0.78 & 0.77 & 0.77 \\
Hypogamy & 0.83 & 0.83 & 0.82 & 0.83 & 0.81 \\
Hypergamy & 0.86 & 0.84 & 0.85 & 0.83 & 0.81 \\
\hline Total & 0.88 & 0.86 & 0.86 & 0.84 & 0.82 \\
\hline & & $\mathbf{3 r d}$ birth probability & \\
Homogamy (Low) & 0.38 & 0.38 & 0.38 & 0.37 & 0.38 \\
Homogamy (Medium) & 0.20 & 0.18 & 0.20 & 0.20 & 0.21 \\
Homogamy (High) & 0.19 & 0.18 & 0.19 & 0.20 & 0.22 \\
Hypogamy & 0.25 & 0.25 & 0.23 & 0.23 & 0.24 \\
Hypergamy & 0.27 & 0.25 & 0.24 & 0.24 & 0.26 \\
\hline Total & 0.32 & 0.30 & 0.28 & 0.27 & 0.27 \\
\hline
\end{tabular}

Source: Author's own estimations based on IPUMS data for the 1991 and 2001 censuses and on EL.STAT. data for the 2011 census. 
Figure 2:

Differences in the effective reproductive lifetime* between highly educated homogamous couples and other educational pairings (in years) - (five-year groups of the 1945-1969 birth cohorts)

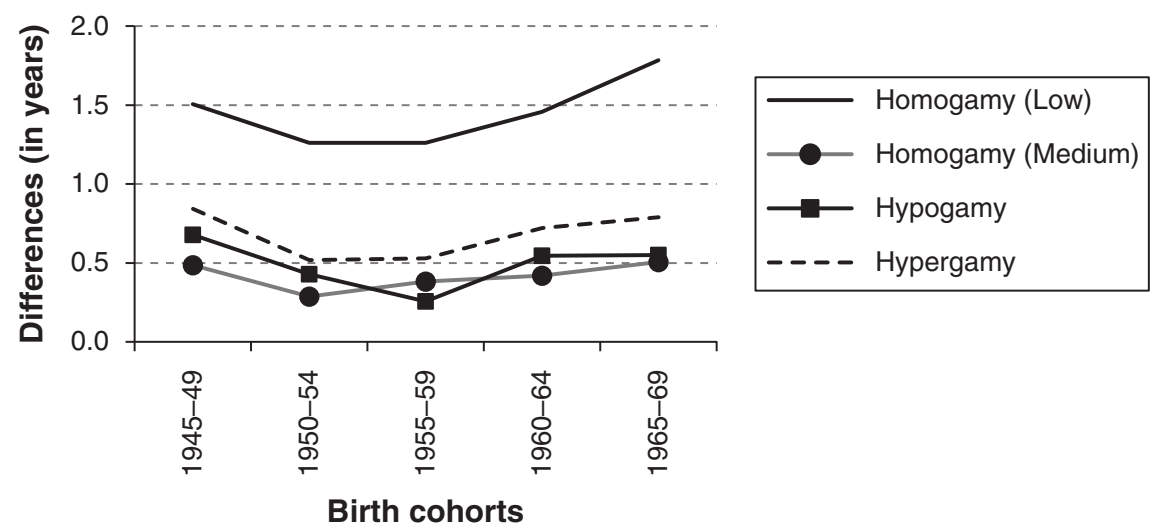

Source: Author's own estimations based on IPUMS data for the 1991 and 2001 censuses and on EL.STAT. data for the 2011 census.

*Difference between the mean ages at the last and the first birth

less educated homogamous couples (between 1.3 and 1.8 years), and were smaller when we compared these couples with the other educational pairings (between onequarter and less than one year).

\section{Conclusions and discussion}

We used census data to analyse fertility patterns by couples' educational levels for female birth cohorts born between 1945 and 1969. In line with recent studies (Esteve et al. 2012; Van Bavel, 2012; Grow and Van Bavel 2015), we found that the increase in female educational levels was accompanied by an increase in the incidence of hypogamy (the woman is more educated than the man) and of medium and high homogamy. This finding suggests a shift away from the traditional pattern of educational hypergamy (women marrying up).

The findings indicate that the homogamous couples tended to have higher completed fertility than heterogamous couples. Nevertheless, this result relied on the relatively high fertility levels among the less educated homogamous partners, as the homogamous couples with medium and (in particular) high levels of education had lower fertility than any other educationally heterogamous pairing (hypergamy or hypogamy).

The differentials in fertility patterns by couples' levels of education appear to be related more to the tempo than the quantum of fertility, with the notable exception 
of the completed fertility levels among less educated homogamous couples. Across all birth cohorts, the completed fertility levels were around $25 \%$ higher among this particular educational pairing than among the other educational pairings. This gap was based on different probabilities of having a second or a third birth, but not on the probability of having a first birth. In fact, the chances of having a first birth were almost equal across educational pairings and birth cohorts. It is, however, clear that entry into motherhood occurred at the highest ages among the highly educated homogamous couples. In addition, our findings suggest that the differences in the timing of first childbearing between highly and less educated homogamous couples became more pronounced, while the differences between these couples and the remaining educational pairings remained at rather constant levels.

Our finding that the highly educated homogamous partners entered parenthood relatively late in life is in line with previous empirical results (Corijn et al. 1996; Nitsche et al. 2015). In addition, our finding that the discrepancies in the mean age at first motherhood increased between highly educated and less educated homogamous couples is similar to a conclusion reached by Rendall and colleagues (2010) in their analysis of the link between women's educational levels and fertility in Greece. However, we are taking their findings a step further by arguing that their results are probably more closely related to differences in the first birth rates between highly and less educated homogamous couples than between highly and less educated women. Our results on similar distributions of childlessness by couples' educational levels and birth cohorts contrast with those of other studies (Wirth 2007, cited by Nitsche et al. 2015; Bauer and Jacob 2009). While contextual factors may play a role, these discrepancies are probably related to our decision to examine permanently childless women instead of the proportion of childless women at an age that does not necessarily mark the end of the reproductive lifetime.

The trend towards low fertility among highly educated homogamous couples appears to run counter to the ongoing transformation of gender roles and relations, which can be seen as a precondition for gender egalitarianism, and which could in turn lead to higher fertility. Nevertheless, increasing female educational levels do not necessarily translate into the levels of gender equality that are expected by highly educated women. It has been asserted that a sufficient level of gender equity is a necessary precondition for more fertility (Esping-Andersen and Billari 2015), but achieving gender equity is a long-term process that involves adapting social institutions and family relationships to meet the new expectations. Over time, movement towards gender equality may be expected to result in higher fertility. However, it is important to keep in mind that gender equality has three dimensions: employment, financial resources, and family work. Thus, gender equality does not simply mean 'sameness of distribution', but encompasses the ability to maintain a household, the degree of agency, the capability to choose, and the degree of gender equity in household and care work (Neyer et al. 2013). Highly educated 'power couples' (Dribe and Stanfors 2010) in Sweden have likely come close to achieving gender equality, which may be why they have high fertility levels. But the highly 
educated homogamous couples of our birth cohorts in Greece appear to have made less progress in several key dimensions of gender equality.

In addition, institutional aspects of fertility, and particularly the lack of adequate policies supporting women in combining employment with motherhood, likely contribute substantially to both the very late timing of entry into motherhood and the low fertility levels among highly educated homogamous couples. A number of studies have suggested that family policies mediate the growth of socio-economic differentials in fertility (Schulze and Tyrell 2002), and that fertility is positively related to policies that make it easier for women to balance their work and family responsibilities (Thévenon 2011). In a conservative 'southern European' family policy model, such as that of Greece, the low level of institutional compatibility between family and employment appears to lead highly educated women to delay childbearing (Rendall et al. 2010), and is probably the main reason for the late and relatively low fertility among highly educated homogamous Greek couples.

However, the extent to which gender equality is associated with fertility may depend on people's perceptions of gender equality, and on how those perceptions align with their values. This dynamic is probably behind our finding that less educated homogamous couples had the highest fertility levels. While this result may appear to contradict micro-economic models of the family, it does not necessarily indicate that there is no task specialisation between less educated partners. However, it is very likely that among these couples this task specialisation process is determined not by an (economic) rationale, but by their adherence to traditional gender roles; i.e., to the assumption that the man will participate in the labour market and the woman will handle the family work responsibilities. Indeed, if this one(male)-breadwinner model is perceived as fair and just by less educated partners who share traditional values, these couples may be expected to have relatively high fertility, despite the persistence of gender inequality. Moreover, selection effects probably apply to this particular educational pairing, whereby less educated partners become more selective across cohorts, specifically with regard to observed and perceived gender equality and attitudes towards paid and unpaid work, which may in turn lead to higher levels of completed fertility.

One limitation of our study, which is indeed characteristic of the cohort perspective, is that it does not take into consideration the most recent socioeconomic developments in Greece. The reproductive behaviour of the birth cohorts we studied occurred in a context in which the changes in gender roles had been modest; i.e., in a transitional period in terms of gender egalitarianism. Thus, the fertility behaviour of the cohorts may have been more affected by gender equality expectations than by the ongoing changes in gender equality in employment, financial resources, and family work. In other words, the differences in fertility levels by the partners' educational levels could display different patterns among the cohorts born in 1970 onwards, and particularly among highly educated women with an equally or less educated male partner. Future research should address these issues, and especially the shifts in male and female breadwinning patterns. 
A further limitation of our study lies in the data we used for the estimations. Fertility patterns by the couples' educational levels were investigated using data on the fertility of women who were in an educationally dissimilar couple. Accordingly, our fertility indicators provide more information about the female than the male partners, and mainly reflect the fertility of women living in a couple, rather than the fertility of couples as such.

However, we believe that educational pairing is likely to be an important topic in the investigation of human reproduction, particularly given that the increase in female educational levels and the shifts in traditional gender roles are leading to changes in fertility decision-making processes. Our cohort approach provides useful insights into how differences in fertility are associated with couples' educational levels, an issue that has seldom been analysed in the previous demographic literature. Our approach makes it possible to estimate different fertility schedules with respect to entry into parenthood, fertility by birth order, and completed cohort fertility for various educational pairings. Thus, our study contributes to the discussion on the role of couples' educational attainment in shaping fertility outcomes.

\section{Acknowledgments}

The author would like to thank IPUMS International and the Hellenic Statistical Authority (EL.STAT.), and particularly S. Kouziou, for providing the data. Helpful comments from two external reviewers, editors, participants in the conference on education and reproduction in low-fertility settings organised by the Vienna Institute of Demography (2-4 December 2015), Werner Richter, and Kate Michalopoulou are also gratefully acknowledged.

\section{References}

Bagavos C. 2010. Education and childlessness: the relationship between educational field, educational level, employment and childlessness among Greek women born in 1955-1959. Vienna Yearbook of Population Research 8, 51-75.

Bagavos C. and A. Tragaki 2014. Economic uncertainty and fertility outcomes in Greece: the "structural"-"distributional" effect of education level and employment status on male and female fertility levels. Paper presented at the European Population Conference 2014, Budapest, 25-28 June.

Bauer G. and M. Jacob 2009. The influence of partners' education on family formation Equalsoc Working Paper 2009/4. http://www.researchgate.net/publication/228388443.

Becker G. S. 1960. An economic analysis of fertility. In Demographic and Economic Change in Developed Countries, ed. G. S. Becker 209-231. Princeton University Press.

Becker G. S. 1993. A treatise on the family. Enlarged edition. Cambridge, MA: First Harvard University Press. 
Chen R. B. and S. P. Morgan 1991. Recent trends in the timing of first births in the United States, Demography 28(4): 513-533.

Corijn M., A. Liefbroer and J. de Jong Gierveld 1996. It Takes Two to Tango, Doesn't It?. The Influence of Couple Characteristics on the Timing of the First Child. Journal of Marriage and the Family 59(1): 117-126.

Dribe M. and M. Stanfors 2010. Family life in power couples. Continued childbearing and union stability among the educational elite in Sweden, 1991-2005. Demographic Research 23(30): 847-877.

EL.STAT 2015. 2011 Census data. Obtained by http://www.statistics.gr/el/ statistical-data-request, after special request.

Esping-Andersen G. and F. C. Billari 2015. Re-theorizing Family Demographics. Population and Development Review 41(1): 1-31.

Esteve A., J. García-Román and I. Permanyer 2012. The gender-gap reversal in education and its effect on union formation: The end of hypergamy? Population and Development Review 38(3): 535-546.

Fraser N. 1994. After the family wage: Gender equity and the welfare state. Political Theory 22(4): 591-618.

Grow A. and J. Van Bavel 2015. Assortative mating and the reversal of gender inequality in education in Europe: An agent-based model. PLOS One, http://www.plosone.org/article/ fetchObject.action?uri=info:doi/10.1371/journal.pone.0127806\&representation=PDF.

Hener T. 2010. Do couples bargain over fertility? Evidence based on child preference data. Ifo Working Paper No. 92. https://www.cesifo-group.de/portal/page/portal/ 96878EC443EB4BE6E04400144FAFBA7C.

Hoem J., G. Neyer and G. Andersson 2006. Education and childlessness: The relationship between educational field, educational level, and childlessness among Swedish women born in 1955-59, Demographic Research 14(15): 331-380.

Huber S. and M. Fieder 2011. Educational homogamy lowers the odds of reproductive failure. PLoS 6(7): 1-6.

IPUMS 2015. 1991 and 2001 censuses data for Greece. Obtained by https://international. ipums.org/international/ upon special request.

Kalmijn, M. 1991. Shifting boundaries: Trends in religious and educational homogamy. American Sociological Review 56(6): 786-800.

Klesment M. and J. Van Bavel 2015. The reversal of the gender gap in education and female breadwinners in Europe. Families And Societies Working Paper 26. Stockholm University, Department of Sociology. http://www.familiesandsocieties.eu/wp-content/uploads/2015/ 01/WP26KlesmentVanBavel.pdf.

Kravdal $\varnothing$. and R. R. Rindfuss 2008. Changing relationships between education and fertility a study of women and men born 1940-64. American Sociological Review 73(5): 854-873.

Lagoudakou, K. and C. Bagavos 2016. Economic crisis and changes in life cycle stages of individuals: a temporal and spatial approach with the application of Sullivan method. Paper presented at the International Conference Journées Internationales du Travail, Athens, 11-14 May. 
Lesthaeghe R. 1995. The second demographic transition in Western countries: an interpretation. In Gender and family change in industrialized countries, ed. K. O. Mason and A.-M. Jensen, 17-62. Oxford: Clarendon Press.

Mascie-Taylor C. G. N. 1986. Assortative mating and differential fertility. Biology and Society 3(4): 167-170.

McDonald P. 2000a. Gender equity, social institutions and the future of fertility. Journal of Population, Research 17(1): 1-16.

McDonald P. 2000b. Gender equity in theories of fertility transition. Population and Development Review 26(3): 427-439.

Neyer G., T. Lappegard and D. Vignoli 2013. Gender equality and fertility: Which gender equality matters? European Journal of Population 29(3): 245-272.

Nisén J., P. Martikainen, K. Silventoinen and M. Myrskylä 2014. Age-specific fertility by educational level in the Finnish male cohort born 1940-1950. Demographic Research 31(5): 119-136.

Nitsche N., A. Matysiak, J. Van Bavel and D. Vignoli 2015. Partners' educational pairings and fertility across Europe. Families and Societies Working Papers Series, n. 38. http:// www.familiesandsocieties.eu/wp-content/uploads/2015/06/WP38NitscheEtA12015.pdf.

Oppenheimer V. K. 1997. Women's employment and the gain to marriage: The specialization and trading model. Annual review of sociology 23: 431-453.

Rendall M., E. Aracil, C. Bagavos, C. Couet, A. Derose, P. Digiulio, T. Lappegård, I. RobertBobée, M. Rønsen, S. Smallwood and G. Verropoulou 2010. Increasingly heterogeneous ages at first birth by education in Southern European and Anglo-American familypolicy regimes: A seven-country comparison by birth cohort. Population Studies 64(3): 209-227.

Schulze H. and H. Tyrell 2002. What happened to the European family in the 1980s? The polarization between the family and other forms of private life. In Family life and family policies in Europe, Volume 2, Problems and Issues in Comparative Perspective, ed. F. Kaufmann, A. Kuijsten, H. Schulze and K. P. Strohmeier, 69-119. Oxford: Oxford University Press.

Sobotka T., E. Beaujouan K. Neels, R. R. Rindfuss and Z. Brzozowska 2015. Education and fertility in low-fertility countries: A long-term perspective. Paper presented at the International Conference on Education and Reproduction in Low-Fertility Settings, Vienna, 2-4 December 2015.

Sorenson A. M. 1989. Husbands' and wives' characteristics and fertility decisions: A diagonal mobility model. Demography 26(1): 125-135.

Testa M. R., L. Cavalli and A. Rosina 2014. The effect of couple disagreement about childtiming intentions: A parity-specific approach. Population and Development Review 40(1): $31-53$.

Thévenon O. 2011. Family policies in OECD countries: A comparative analysis, Population and Development Review 37(1): 57-87.

Thomson, E. 1990. Two in one: structural models of couple behaviour. In Family variables: Conceptualization, measurement and use, ed. C. W. Draper and A. C. Marcos, 129-142. Newbury Park, CA: Sage. 
Thomson E. 1997. Couple childbearing desires, intentions, and births. Demography 34(3): 343-354.

Thomson E., M. Winkler-Dworak and S. Kennedy 2013. The standard family life course: An Assessment of variability in life course pathways. In Negotiating the life course: Stability and change in life pathways, ed. A. Evans and J. Baxter, 35-52. Dordrecht: Springer.

Tragaki A. and C. Bagavos 2014. Male fertility in Greece: trends and differentials by education level and employment status. Demographic Research 31(6): 137-160.

Tsimbos C. 2006. The Impact of migration on growth and ageing of the population in a new receiving country: The case of Greece, International Migration 44(4): 231-254.

Van Bavel J. 2010. Choice of study discipline and the postponement of motherhood in Europe: the impact of expected earnings, gender composition and family attitudes, Demography 47(2): 439-458.

Van Bavel J. 2012. The reversal of gender inequality in education, union formation and fertility in Europe. Vienna Yearbook of Population Research 10: 127-154.

Wirth H. 2007. Kinderlosigkeit von hochqualifizierten Frauen und Männern im Paarkontext - Eine Folge von Bildungshomogamie? In Ein Leben ohne Kinder. Kinderlosigkeit in Deutschland, ed. K. Dirk and M. Kreyenfeld, 137-170. Wiesbaden: VS Verlag.

Wood J., K. Neels and T. Kil 2014. The educational gradient of childlessness and cohort parity progression in 14 low-fertility countries. Demographic Research 31(46): 1365-1416.

Zhang L. 2011. Male fertility patterns and determinants. The Springer Series on Demographic Methods and Population Analysis 27. Springer editions. 


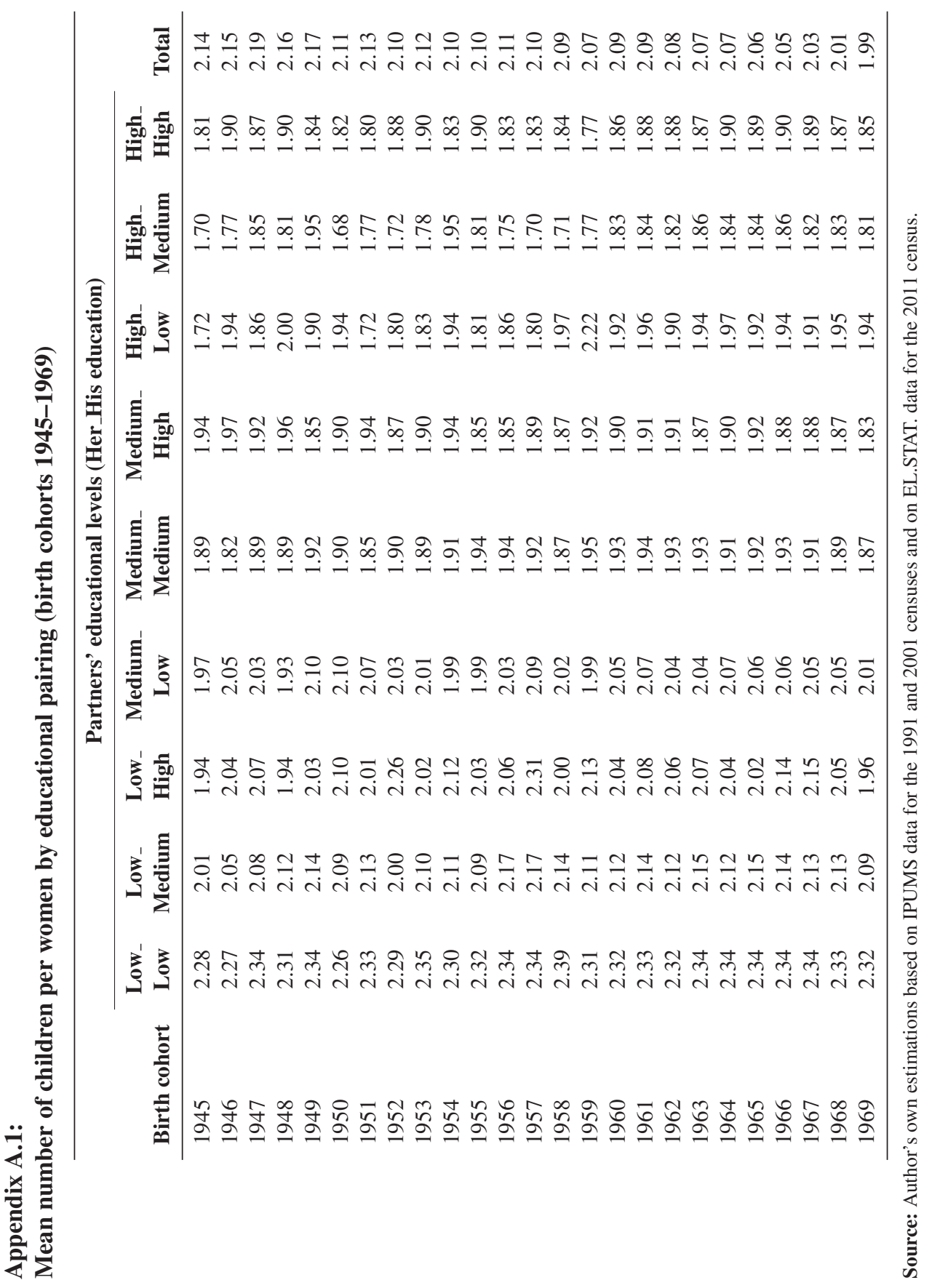


